\title{
The pattern of mucocutaneous disorders in HIV - infected children attending care and treatment centres in Dar es Salaam, Tanzania Millembe F Panya ${ }^{\dagger 1}$, Yassin M Mgonda*2 and Augustine W Massawe ${ }^{\dagger 1}$
}

\author{
Address: ${ }^{1}$ Department of Paediatrics and Child Health, Muhimbili University of Health and Allied Sciences, Muhimbili, Dar es Salaam, Tanzania \\ and ${ }^{2}$ Department of Internal Medicine, Muhimbili University of Health and Allied Sciences, Muhimbili, Dar es Salaam, Tanzania \\ Email: Millembe F Panya - millembepanya@yahoo.com; Yassin M Mgonda* - ymgonda@muhas.ac.tz; \\ Augustine W Massawe - amassawe@muhas.ac.tz \\ * Corresponding author †Equal contributors
}

Published: 14 July 2009

BMC Public Health 2009, 9:234 doi:10.1 | 86/ | 47/-2458-9-234

This article is available from: http://www.biomedcentral.com/I47/-2458/9/234

(C) 2009 Panya et al; licensee BioMed Central Ltd.

This is an Open Access article distributed under the terms of the Creative Commons Attribution License (http://creativecommons.org/licenses/by/2.0), which permits unrestricted use, distribution, and reproduction in any medium, provided the original work is properly cited.
Received: 26 January 2009

Accepted: 14 July 2009

\begin{abstract}
Background: HIV/AIDS is associated with a wide range of mucocutaneous disorders some of which are useful in the clinical staging and prognosis of the syndrome. There is paucity of information regarding the prevalence and pattern of mucocutaneous disorders among HIV infected children attending paediatric Care and Treatment Centres (CTC) in Dar es Salaam. Objective To determine the prevalence and pattern of mucocutaneous disorders among HIV infected children attending public paediatric 'Care and Treatment Centres' in Dar es Salaam.
\end{abstract}

Methods: This was a cross sectional descriptive study involving public paediatric 'Care and Treatment Centres' in Dar es Salaam. Clinical information was obtained using a questionnaire. Dermatological examination was carried out in daylight. Investigations were taken as appropriate. Data was analysed using the Statistical Package for Social Sciences (SPSS) program version 10.0. Chi-squared and Fisher's exact tests were utilized. A p-value of less than 0.05 was considered statistically significant.

Results: Three hundred and forty seven HIV infected children ( $52 \%$ males) attending CTCs were recruited into the study. Mucocutaneous disorders were encountered in $85 \%$ of them. There was no gender difference in the prevalence of the infective mucocutaneous disorders but males had a higher prevalence of non-infective/inflammatory dermatoses $(58 \%)$ than females $(42 \%)(p=0.02)$. Overall, mucocutaneous disorders (infective + non infective) were more prevalent in advanced stages of HIV disease. Children with advanced HIV disease had a significantly increased frequency of fungal and viral infections ( $43 \%$ and $25 \%$ respectively than those with less advanced disease; $24 \%$ and $13 \%$ respectively $(p=0.01)$. Seventy four percent of the HIV-infected children with mucocutaneous disorders were already on ART.

Conclusion: Mucocutaneous disorders among HIV infected children attending Care and Treatment Centres are common and highly variable. Comprehensive management should also emphasize on the management of mucocutaneous disorders. 


\section{Background}

Mucocutaneous disorders are common in both HIVinfected and non-infected children. Human Immunodeficiency virus infection causes a severe cellular immunodeficiency, which results in a greater susceptibility to infectious, inflammatory and malignant conditions [1]. In early HIV infection, most of the mucocutaneous dermatoses are similar to those observed in the non infected children. With progressive immunosuppression, mucocutaneous eruptions, become more common and include patterns which are atypical, difficult to diagnose and resistant to treatment [2-4]. Candida albicans infection presenting as extensive oral thrush or recalcitrant monilial diaper dermatitis is the most common and often the first manifestation of paediatric HIV infection. Bacterial infections including severe forms of staphylococcal impetigo, ecthyma and furuncles are also common [3,4]. Extensive molluscum contagiosum, Herpes simplex infection and plane warts are also common with lesions which are more widely distributed and very difficult to treat $[3,4]$.

Non infective/inflammatory dermatoses like seborrhoeic eczema and Kaposi's sarcoma, which are common in adults in whom they become more widespread and refractory to treatment as CD4+ T-cell count declines, are exceptional in children [4-6]. Pruritic Papular Eruption of HIV/ AIDS (PPE) is common in both adults and children with marked depletion of CD4+ T-lymphocytes [5,7].

In this era of Anti - Retroviral-Therapy (ART), the immune reconstruction induced by ART would be expected to significantly reduce the prevalence of many dermatological diseases as a consequence of a profound suppression of viral replication with the accompanying increase in CD4+ T-cell count $[1,7]$.

In Dar es Salaam, there is still paucity of information regarding the prevalence of mucocutaneous disorders among HIV infected children attending 'Care and Treatment Centres'. This study was conducted in order to address this lack of data; the main objective being to describe the prevalence and pattern of mucocutaneous disorders in HIV infected children attending these centres in Dar es Salaam.

\section{Methods}

\section{Study design and Setting}

This was a descriptive cross-sectional study conducted at the public Paediatric HIV Care and Treatment Centres in Dar es Salaam.

\section{Sampling technique}

Study subjects were recruited using the 'sampling proportional to size' technique whereby, the number of children to be included from each CTC depended on the pre-deter- mined number of children visiting that centre. A sampling fraction of $24 \%$ was used to determine the minimum number of children from each centre. All HIV infected children aged up to 17 years, whose parents/guardians gave informed consent, were enrolled consecutively until the required sample size was obtained.

\section{Clinical and laboratory work-up}

All participants were interviewed to obtain demographic and clinical information and whether or not they were on ART. Dermatological examination was done in daylight. Diagnoses of most dermatoses were done clinically. Where necessary, appropriate laboratory tests like skin scrapings, pus swabs and skin biopsies were performed to confirm the diagnoses. Lymphocyte subsets were determined using a FACS calibur machine (Becton-Dickinson USA 2005).

\section{Clinical staging and immunological classification of HIVI AIDS}

Clinical staging was done according to the WHO paediatric staging of HIV/AIDS [8] while immunologic classification was done according to the CDC immunologic classification for HIV infected infants and children $[9,10]$.

\section{Data analysis}

Statistical analysis was done using the Statistical Package for Social Sciences (SPSS) program version 10.0 [11]. Chisquared test was used for categorical variables while Fisher's exact test was used when the number was less than 5. A p-value of less than 0.05 was considered statistically significant.

\section{Ethical Issues}

Ethical clearance was obtained from the Research and Publications Committee of the Muhimbili University of Health and Allied Sciences.

\section{Results}

Age and sex distribution of HIV-infected children attending CTCs

A total of 347 HIV infected children were recruited into the study (Table 1). Of these, 180 (52\%) were males. The

Table I: Distribution of HIV infected children attending HIV CTC by age and sex $(n=347)$

\begin{tabular}{llll}
\hline Age group (years) & $\begin{array}{l}\text { Males } \\
\mathrm{n}(\%)\end{array}$ & $\begin{array}{l}\text { Females } \\
\mathrm{n}(\%)\end{array}$ & $\begin{array}{l}\text { Total } \\
\mathrm{n}(\%)\end{array}$ \\
\hline $0-5$ & $61(34)$ & $44(26)$ & $105(30)$ \\
$6-10$ & $77(43)$ & $78(47)$ & $155(45)$ \\
$11-15$ & $36(20)$ & $39(23)$ & $\begin{array}{l}75(22) \\
12(3)\end{array}$ \\
$16-\geq 17$ & $6(3)$ & $6(4)$ & $347(100)$ \\
\hline Total & $180(52)$ & $167(48)$ & 3 \\
\hline
\end{tabular}


age ranged from 6 months to 16 years (mean 7.8 years \pm 3.8 SD).

Overall, 85\% (294/347) had mucocutaneous disorders. Eighty seven percent of the males and $83 \%$ of the females had one or more types of mucocutaneous disorders $(\mathrm{p}=$ 0.29 ). Among children aged up to 5 years, $88 \%$ had mucocutaneous disorders while for those aged 6 years and above, the prevalence was $83 \%(\mathrm{p}=0.59)$.

\section{The pattern of mucocutaneous disorders among HIV infected children}

A wide range of mucocutaneous disorders was encountered as shown in table 2. The infectious dermatoses (fungal, viral, bacterial and parasitic infections) accounted for the majority of the skin diseases $(87 \%)$ while the inflammatory dermatoses (PPE, atopic dermatitis, seborrhoeic dermatitis and non specific dermatitis) accounted for $69 \%$. Many children had multiple skin conditions and were therefore counted more than once in certain situations. When specific mucocutaneous disorders were analysed, PPE was the commonest condition present in $45.5 \%$ followed by superficial fungal infections in $40 \%$ of the children. The most frequent superficial fungal infection was tinea capitis, occurring in $16 \%$ while the least frequent was tinea cruris found in only one child. Viral and

Table 2: Mucocutaneous disorders in HIV infected children attending Care and Treatment Centres in Dar es Salaam ( $n=$ 294)

\begin{tabular}{lll}
\hline Mucocutaneous disorder & N & $\%$ \\
\hline Non infectious inflammatory dermatoses & $\mathbf{2 0 2}$ & $\mathbf{6 9}$ \\
Pruritic papular eruption (PPE) & 134 & 45.5 \\
$\quad$ Atopic dermatitis & 31 & 10.5 \\
Seborrheic dermatitis & 24 & 8 \\
Non specific dermatitis & 13 & 4.4 \\
Infectious dermatoses & $\mathbf{2 5 6}$ & $\mathbf{8 7}$ \\
Superficial fungal infections & $\mathbf{I I}$ & $\mathbf{4 0}$ \\
Tinea capitis & 47 & 16 \\
Tinea unguim & 31 & 10.5 \\
Tinea corporis & 28 & 9.5 \\
Pityriasis versicolor & 11 & 4 \\
Oral candidosis & 11 & 4 \\
Tinea cruris & 1 & 0.3 \\
Viral infections & $\mathbf{6 8}$ & $\mathbf{2 3}$ \\
Plane warts & 58 & 20 \\
Molluscun contagiosum & 13 & 4 \\
Herpes simplex & 4 & 1.4 \\
Herpes zoster & 2 & 0.7 \\
Bacterial infections & $\mathbf{3 6}$ & $\mathbf{1 2}$ \\
Impetigo & 28 & 9.5 \\
Abscess & 6 & 2.0 \\
Cellulitis & 3 & 1.0 \\
Scabies & $\mathbf{3 4}$ & $\mathbf{1 2}$ \\
Kaposis Sarcoma & $\mathbf{I}$ & $\mathbf{0 . 3}$ \\
Drug reaction & $\mathbf{I}$ & $\mathbf{0 . 3}$ \\
Nail hyperpigmentation & $\mathbf{I}$ & $\mathbf{0 . 3}$ \\
\hline
\end{tabular}

bacterial skin infections were found in $23 \%$ and $12 \%$ respectively. Plane warts found in $20 \%$, were the most frequent viral infections while herpes zoster present in 2 patients was the least frequent. The commonest bacterial skin infection was bullous impetigo in $9.5 \%$. The only neoplasm encountered was Kaposi's sarcoma present in one who had been on ART for 1 month. Two children had nail hyperpigmentation while one child had severe drug eruption (Stevens-Johnson syndrome) induced by co-trimoxazole.

Table 3 shows the distribution of the different types of mucocutaneous disorders by age-groups. Fungal infections were more prevalent in the older children aged above 15 years $(58 \%)$, while those aged 5 years and below were the least $(20 \%)$ affected $(\mathrm{p}=0.01)$. The prevalence of viral, bacterial, and inflammatory cutaneous disorders did not show any significant age-group difference ( $\mathrm{p} \geq 0.25$ ).

\section{The pattern of mucocutaneous disorders by WHO and CDC level of immunosuppression}

Table 4 shows the prevalence of mucocutaneous disorders by WHO clinical staging and CDC level of immunosuppression. The prevalence of mucocutaneous disorders was highest in the advanced paediatric WHO stages III (94\%) and IV (100\%) and relatively lower in stage II $(76 \%)$ while it was lowest $(29 \%)$ in stage I $(\mathrm{p}<0.01)$. Likewise, children with severe immunosuppression by CDC criteria had the highest prevalence of mucocutaneous disorders $(97 \%)$, followed by those with moderate immunosuppression $(84.5 \%)$ while children with no evidence of immunosuppression had the lowest $(71 \%)$ prevalence ( $\mathrm{p}$ $<0.01)$.

Of the 294 children with mucocutaneous disorders, about three- quarters (74\%) were on ART according to the Tanzanian National HIV treatment guidelines. Of these, only $20 \%$ had been on ART for a period longer than 12 months. The majority (49\%), had been on ART for a period between six and twelve months while one-third (31\%) had used ART for less than 6 months.

\section{Discussion}

From this study, $85 \%$ of HIV/AIDS paediatric patients attending CTCs in Dar es Salaam suffer from a wide range of mucocutaneous disorders. A high prevalence of skin diseases among HIV infected children similar to ours has also been reported by Montri et al in Thailand (83\%) [12] and De Carvalho OV et al in Brazil (82.5\%) [13]. Other studies have reported different prevalence levels $[1,14]$ indicating a wide regional variation. According to Luminous LM et al, children less than five years of age, are the least affected than the older ones [15]. In this study, children aged less than 5 years were almost equally affected as those aged 6 years and above regardless of sex. Siriwan W 
Table 3: Distribution of types of mucocutaneous disorders among HIV infected children by age

\begin{tabular}{|c|c|c|c|c|c|c|}
\hline \multirow[t]{2}{*}{ MUCOCUTANEOUS DISORDER } & \multicolumn{4}{|c|}{ AGE GROUP (years) } & \multirow[t]{2}{*}{ Total } & \multirow[t]{2}{*}{$\mathrm{P}$-value } \\
\hline & $\begin{array}{l}0-5 \\
n=105(\%)\end{array}$ & $\begin{array}{l}6-10 \\
n=155(\%)\end{array}$ & $\begin{array}{l}I I-15 \\
n=75 \\
(\%)\end{array}$ & $\begin{array}{l}>15 \\
n=12(\%)\end{array}$ & & \\
\hline Inflammatory dermatoses & $66(63)$ & $78(50)$ & $34(45)$ & $8(67)$ & 186 & $0.7 \mathrm{I}$ \\
\hline Fungal infections & $21(20)$ & $60(39)$ & $30(40)$ & $7(58)$ & 118 & 0.01 \\
\hline Viral infections & $15(14)$ & $28(14)$ & $22(29)$ & $3(25)$ & 68 & 0.35 \\
\hline Bacterial infection & $10(9.5)$ & $17(11)$ & $9(12)$ & $0(0.0)$ & 36 & 0.93 \\
\hline Infestation (scabies) & $14(13)$ & II (7) & $7(9)$ & $2(17)$ & 34 & 0.25 \\
\hline Miscellaneous & $I(I)$ & $0(0)$ & $2(3)$ & $0(0)$ & 3 & 0.76 \\
\hline
\end{tabular}

et al reported the prevalence of mucocutaneous disorders in HIV infected children with severe, moderate and no evidence of immunosuppression as $62 \%, 43 \%$ and $20 \%$ respectively [14]. In this study, the prevalence of mucocutaneous disorders among children with severe, moderately severe and no evidence of immunosuppression was $97 \%, 84.5 \%$ and $71 \%$ respectively and the differences were statistically significant. All these studies indicate that the risk of acquiring mucocutaneous disorders for HIV infected children rises as the level of immunosuppression advances.

Infections are the most frequent cause of mucocutaneous disorders among HIV infected children $[1,3,4,14]$ which has also been shown in this study. The increased incidence of skin infections is attributed to the depletion of the Langerhan's cells responsible for the mucocutaneous immunological system [13]. The distortion of the cutaneous immune system is also responsible for the emergence of a variety of non-infectious inflammatory dermatoses frequently encountered among HIV/AIDS individuals like PPE. In this study PPE was present in nearly half (45.5\%) of the affected children.

In our study, Kaposi's sarcoma (KS) was seen in only one child indicating that this malignancy is rare among HIV infected children, which is similar to what was reported by el Hachem $M$ et al [4]. However, other studies have reported a significant rise in childhood KS among HIV infected children. Ziegler et al reported that the incidence of KS had risen more than 40-fold in the era of HIV [16]. Similarly Athale $\mathrm{OH}$ et al observed an increased incidence of KS in HIV infected Zambian children [17]. It is surprising that, only one child was found to have a drug reaction (Stevens-Johnson syndrome). This finding probably does not reflect a true picture and calls for an appropriately designed follow-up rather than a cross-sectional study in order to assess the effects of all drugs administered at CTCs.

Nearly $75 \%$ of children with mucocutaneous disorders were already on ART according to the Tanzanian National Guidelines on Treatment of HIV/AIDS. The use of ART has shown a significant reduction in the prevalence of some of the mucocutaneous disorders in HIV infection as a consequence of an increase in CD4+ T cell lymphocytes [1]. It was not possible to demonstrate this effect in our study, because of the study design, which was cross-sectional rather than follow-up. The apparent high prevalence of mucocutaneous disorders among these children, who were already on ART at the time of this study, could be due to the short ART duration. The majority of these children (49\%) were on ART for six to twelve months, while onethird had ART for less than six months and only about

Table 4: Prevalence of mucocutaneous disorders among HIV infected children by WHO and CDC disease progression $(\mathrm{n}=347$ )

\begin{tabular}{|c|c|c|c|c|}
\hline & $\begin{array}{l}\text { Mucocutaneous disorders: } \\
\text { Present } \\
\mathrm{n}=294(\%)\end{array}$ & $\begin{array}{l}\text { Mucocutaneous disorders: } \\
\text { Absent } \\
n=53(\%)\end{array}$ & $\begin{array}{l}\text { Total } \\
\mathrm{n}=347(\%)\end{array}$ & p-value \\
\hline \multicolumn{5}{|c|}{ WHO paediatric stage } \\
\hline I & $2(29)$ & $5(7 I)$ & $7(2)$ & \\
\hline II & $116(76)$ & $37(24)$ & $153(44)$ & $<0.01$ \\
\hline III & $166(94)$ & $11(6)$ & $177(5 \mid)$ & \\
\hline IV & $10(100)$ & $0(0)$ & $10(3)$ & \\
\hline \multicolumn{5}{|c|}{ Immunosuppression level by CDC } \\
\hline No evidence & $74(7 \mathrm{I})$ & $30(29)$ & $104(30)$ & \\
\hline Moderate & $109(84.5)$ & $20(15.5)$ & $129(37)$ & $<0.01$ \\
\hline Severe & $111(97)$ & $3(3)$ & $114(33)$ & \\
\hline
\end{tabular}


$20 \%$ had used it for more than one year. For ART to have a significant effect on mucocutaneous disorders, it needs to be administered for a longer period of time. In a study by Donic I. et al, it was found that the use of ART for about two years reduced significantly the presence of oral candidosis and seborrheic dermatitis [18].

\section{Conclusion}

Mucocutaneous disorders among HIV infected children attending CTCs in Dar es Salaam, regardless of gender or age-group are common, highly variable and mostly infective. Their prevalence rises with deteriorating WHO clinical stage as well as CDC level of immunosuppression. Comprehensive management of HIV infected children attending CTCs should also emphasize on the management of mucocutaneous disorders.

\section{Study limitations}

This was a cross-sectional study which could not offer an opportunity to assess the progress of the pre-existing mucocutaneous disorders, or document on the newly evolving lesions while children continued receiving care from the CTCs

\section{Competing interests}

The authors declare that they have no competing interests.

\section{Authors' contributions}

MFP conceived the study and participated in its design, data collection and write-up. YMM improved and supervised the conceived study, participated in its design, coordinated and approved the final write-up as corresponding author. AWM co-supervised the study and participated in its design. All authors read and approved the final manuscript.

\section{Acknowledgements}

The authors would like to thank Ms R Mpembeni and Mr C Makwaya for their statistical assistance; the Ministry of Health Health and the National Institute of Medical Research for the financial support and finally all parents, nurses and especially the children for their co operation and willingness to participate in the study.

\section{References}

I. Seoane RE, Bellon JM, Gorbindo D, et al:: Role of Antiretroviral Therapy in mucocutaneous manifestations in HIV infected children over a period of two decades. British Journal of Dermatology 2005, 153:382.

2. Myskowski PL, Ahkami R: Dermatological complications of HIV infection. Medical Clinics of North America 1996, 80: 14 I5- 1435.

3. El-Hachem M, Bernadl S, Pianosi G, et al:: Mucocutaneous manifestation in children with HIV infection and AIDS. Paediatric Dermatol 1998, 15:429-434.

4. El Hachem M, Castelli G, Piannosi G, et al:: HIV infection in children: cutaneous manifestations. Int Conf AIDS 1994, 10:262.

5. Mgonda YM, Urassa WK, Lyamuya EF, Pallangyo KJ, Mbena EC: The clinical and immunological characteristics of pruritic papular eruption of HIV disease: Experience from Dar es salaam, Tanzania. Tanzania Medical Journal 200I, 16:1-4.
6. Mgonda YM: Pruritic papular eruption of HIV disease versus cutaneous epidemic Kaposi's sarcoma: could it be used as an AIDS defining illness? Tanzania Medical Journal 2003, 18:5-8.

7. Queiroz ZP, Mcgirt LY, Mamelak AJ, et al.: Cutaneous manifestations of HIV in the era of highly active antiretroviral therapy: An institutional urban clinic experience. Journal of the American Academy of Dermatology 2006, 54:58I-588.

8. Interim WHO clinical staging of HIVIAIDS and HIVIAIDS case definitions for surveillance for Africa Region, Geneva/ Harare. 2004.

9. Centres for Disease Control and Prevention: Revised classification system for HIV-I infection in children less than 13 years of age. MMWR 1994, 43:I-I3.

10. Centres for Disease Control and Prevention: Revision of the CDC Surveillance case definition for acquired immunodeficiency syndrome. MMWR 1987, 36(Supp 135): 135.

II. SPSS Inc version 10.0: The Statistical Package for the Social Sciences. Chicago, II:SPSS Inc; 2004.

12. Montri U, Tarunotai U: Cutaneous manifestations in Children with HIV infection. A 5-year study in Vachira Hospital. Thai Journal of Dermatology 2001, I7:167-174.

13. Oliveira de Carvalho V, Marinoni LP, Martin F, et al:: Dermatological alterations in children with AIDS and their relation to clinical-immunological categories and viral load. An Bras Dermatol 2003, 78:679-692.

14. Siriwan W, Tawatchai D, Chitsanu P, et al.: Mucocutaneous findings in Paediatric AIDS related to degree of immunosupression. Paediatric Dermatology 2003, 20:289.

15. Luminus LM, Mardaresu M, Petrea S, et al.: Cutaneous disorders in HIV infected children. International conference on AIDS 1998, 1 2:574. Absract No 32273

16. Ziegler JL, Katongole-Mbidde E: Kaposi's sarcoma in childhood: an analysis of 100 cases from Uganda and relationship to HIV infection. International Journal of Cancer 1999, 65:200-203.

17. Athale OH, Patil PS, Chintu C, Elem B: Influence of HIV epidemic on the incidence of Kaposi's sarcoma in Zambian children. J Acquir Immune Defic Syndr Hum Retrovirol 1995, 8(I):96-100.

18. Donic I, Vesic S, Jertoric DJ: Oral candidosis and seborrheic dermatitis in HIV infected patients on highly active antiretroviral therapy. HIV medicine 2004, 5:50.

\section{Pre-publication history}

The pre-publication history for this paper can be accessed here:

http://www.biomedcentral.com/1471-2458/9/234/pre pub

Publish with Bio Med Central and every scientist can read your work free of charge

"BioMed Central will be the most significant development for disseminating the results of biomedical research in our lifetime. "

Sir Paul Nurse, Cancer Research UK

Your research papers will be:

- available free of charge to the entire biomedical community

- peer reviewed and published immediately upon acceptance

- cited in PubMed and archived on PubMed Central

- yours - you keep the copyright 